\title{
Three new species of the genus Poltys from Hainan Island, China
}

\section{(Araneae: Araneidae)}

\author{
Guang-Xin Han, Feng Zhang and Ming-Sheng Zhu* \\ College of Life Sciences, Hebei University, Baoding, Hebei 071002, China \\ E-mails: guangxin-han@163.com;dudu06042001@163.com \\ *Deceased
}

\begin{abstract}
Three new species of Poltys spiders collected from Hainan Island, China, are described under the names: Poltys ellipticus sp. nov., P. hainanensis sp. nov. and P. pygmaeus sp. nov.
\end{abstract}

Key words - Araneidae, Poltys, new species, Hainan Island, China.

\section{Introduction}

The genus Poltys was erected by C. L. Koch in 1843 , with Poltys illepidus as the type species. Poltys, one kind of the interesting orb-web spiders, has small adult males and medium to large females with widely separated lateral eyes. Up to present, 40 species have been recorded under the genus Poltys, mainly from most parts of the old-world tropics and sub-tropics with the greatest number of species from southeast Asia (Platnick 2009; Smith 2006). Only 2 species of this genus occur in China, and none is distributed in Hainan Island.

Hainan Island is the southernmost province of China and is totally tropical. During a survey of the spider fauna of Hainan Island in 2008-2009, we collected some araneid specimens by tube and hand capture. After examining and identifying all the specimens, three new Poltys species were recognised, $P$. ellipticus sp. nov., $P$. hainanensis sp. nov. and $P$. pygmaeus sp. nov. We collected the specimens in differernt seasons, but didn't find females matched to males. Smith confirmed the most pairings by raising pairs from egg sacs (Smith 2006).

\section{Materials and Methods}

Terminology is standard for the Araneae. The specimens were examined and illustrated under a Tech XTL-II stereomicroscope. The type specimens are deposited in the Museum of Hebei University, Baoding, China (MHBU).

Carapace length was measured from the anterior margin to the rear margin of the carapace medially. Total length were the sum of carapace and abdomen length, regardless of the petiolus. Eye sizes were measured as the maximum diameter in a dorsal view. Leg measurements were shown as: total length (femur, patella + tibia, metatarsus, tarsus). All measurements are given in millimeters. Abbreviations used in the text: $\mathrm{AME}=$ anterior median eye; $\mathrm{ALE}=$ anterior lateral eye; $\mathrm{PME}=$ posterior median eye; $\mathrm{PLE}=$ posterior lateral eye; $\mathrm{MOA}=$ median ocular area; $\mathrm{TA}=$ terminal apophysis; $\mathrm{E}=$ embolus; $\mathrm{C}=$ conductor; $\mathrm{MA}=$ median apophysis; $\mathrm{PM}=$ paramedian apophysis; $\mathrm{T}=$ tegulum; $\mathrm{ST}=$ subtegulum; $\mathrm{Pc}=$ paracymbium.

\section{Taxonomy}

\section{Genus Poltys C. L. Koch, 1843}

Poltys C. L. Koch 1843: 97; Barrion \& Litsinger 1995: 579; Smith 2006: 46-52; Tanikawa 2007: 91.

Type species. Poltys illepidus C. L. Koch 1843.

Diagnosis. The genus Poltys is similar to Cyphalonotus Simon, but can be easily distinguished from the latter by carapace shape, size and eye arrangement. Poltys species usually have a pear-shaped carapace in dorsal view. Median ocular is quadrangular. PLE are well separated from ALE. Legs I and II are long and slender. Abdomen is basically ovoid. The scape of epigyne is short in female. Male palpal organ is typical araneid sclerites in most species, but some structures are rather simplified. Whereas in Cyphalonotus, the eyes may be slightly separated, PLE is not far away on the carapace; the epigyne has a thinner extended scape; legs I and II are short; males are larger compared to those of Poltys.

\section{Poltys ellipticus sp. nov.} (Figs. 1-5)

Type series. Male holotype: Bawangling National Nature Reserve, Changjiang County, Hainan Province, China, $19^{\circ}$ $01^{\prime} \mathrm{N} 109^{\circ} 06^{\prime} \mathrm{E}$, May 25, 2009, Guang-Xin Han leg. (MHBU); paratype: 1 male, Bawangling National Nature Reserve, Changjiang County, Hainan Province, China, $19^{\circ}$ $01^{\prime} \mathrm{N} 109^{\circ} 06^{\prime} \mathrm{E}$, November 6, 2008, Ming-Sheng Zhu leg. (MHBU).

Diagnosis. This new species closely resembles $P$. 


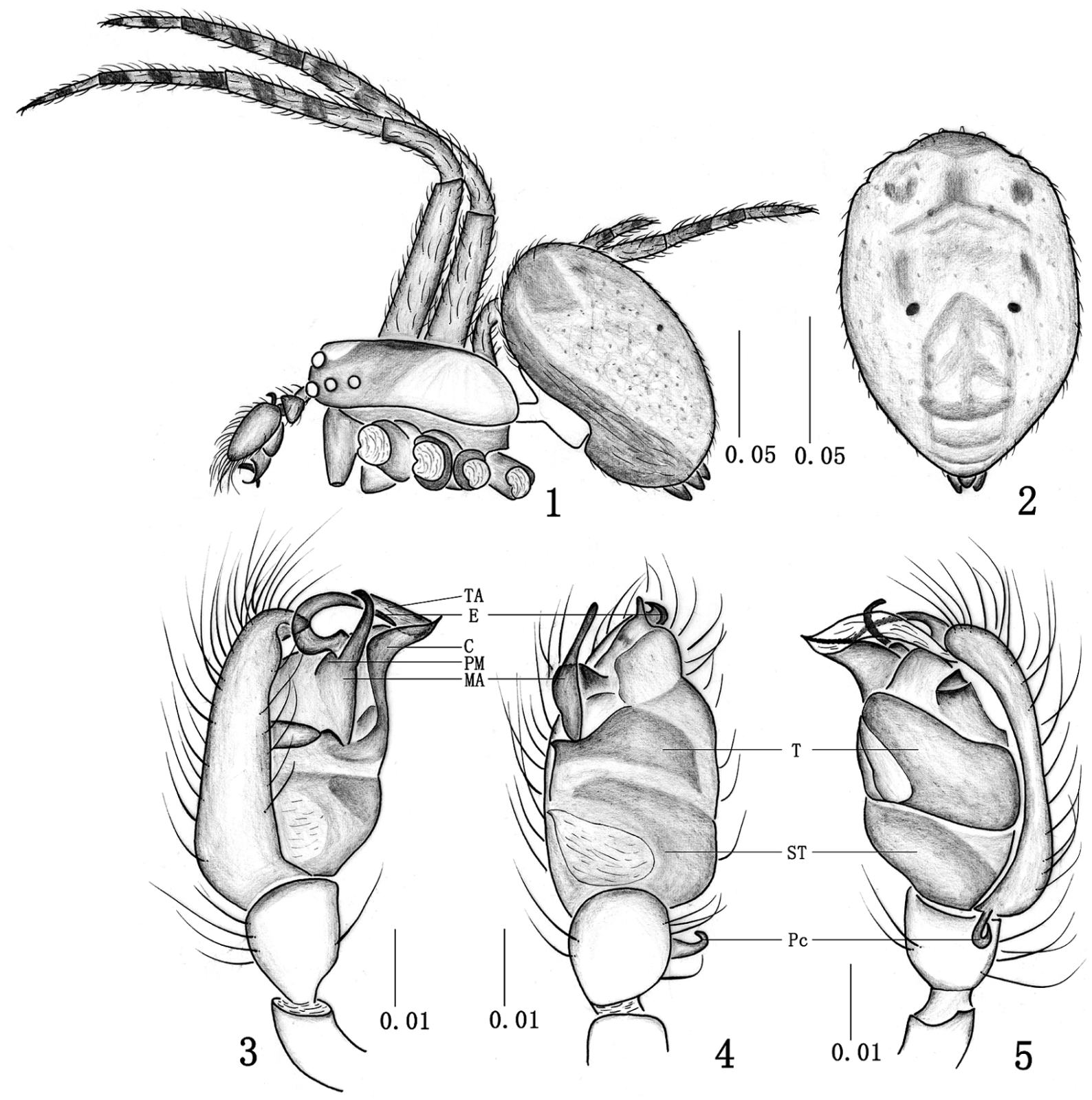

Figs. 1-5. Poltys ellipticus sp. nov., male holotype. - 1, body, lateral view; 2, abdomen, dorsal view; 3, male palp, prolateral view; 4, same, ventral view; 5 , same, retrolateral view. (Scales: $1-2=0.02 \mathrm{~mm}, 3^{-5}=0.01 \mathrm{~mm}$.)

illepidus C. L. Koch, 1843, but can be distinguished from the latter by more slender and curved embolus; by the shapes of terminal apophysis and conductor in male.

Description. Male holotype. Total length 2.50: carapace 1.06 long, 0.78 wide; abdomen 1.44 long, 1.00 wide. Carapace light brown with black median markings, eye tubercle broad and almost without any dip between caput and eye tubercle in lateral view (Fig. 1). Eye sizes and interdistances: AME 0.08, ALE 0.05, PME 0.07, PLE 0.06; AME-AME 0.10, AME-ALE 0.04, PME-PME 0.13, PMEPLE 0.17, ALE-PLE 0.07. MOA 0.23 long, anterior width 0.22 , posterior width 0.29 . Clypeal height very low, much shorter than AME diameter. Chelicera with 4 promarginal teeth. Chelicerae, labium and maxillae dark brown with white edges. Sternum black and hirsute. Legs yelloworange with black rings and markings, without macrosetae flattened into a leaf-shape. Leg measurements: I 3.61 $(1.25+1.27+0.71+0.38) ; \quad$ II $3.37 \quad(1.13+1.20+0.64+$ $0.40)$; III $1.84(0.63+0.65+0.30+0.26)$; IV $2.48(0.90+$ $0.83+0.45+0.30)$. Leg formula: 1243 . Abdomen ovoid, longer than wide, with 2 pairs of brown sigilla midlongitudinally, black speckling and markings on a white ground (Fig. 2). Brown ventrally, black laterally. Palp: embolus rod-shaped, sharply curved, tapering to a point after the curve; conductor plate-shaped, triangular; terminal apophysis slender, lamina-shaped; median apophysis long 

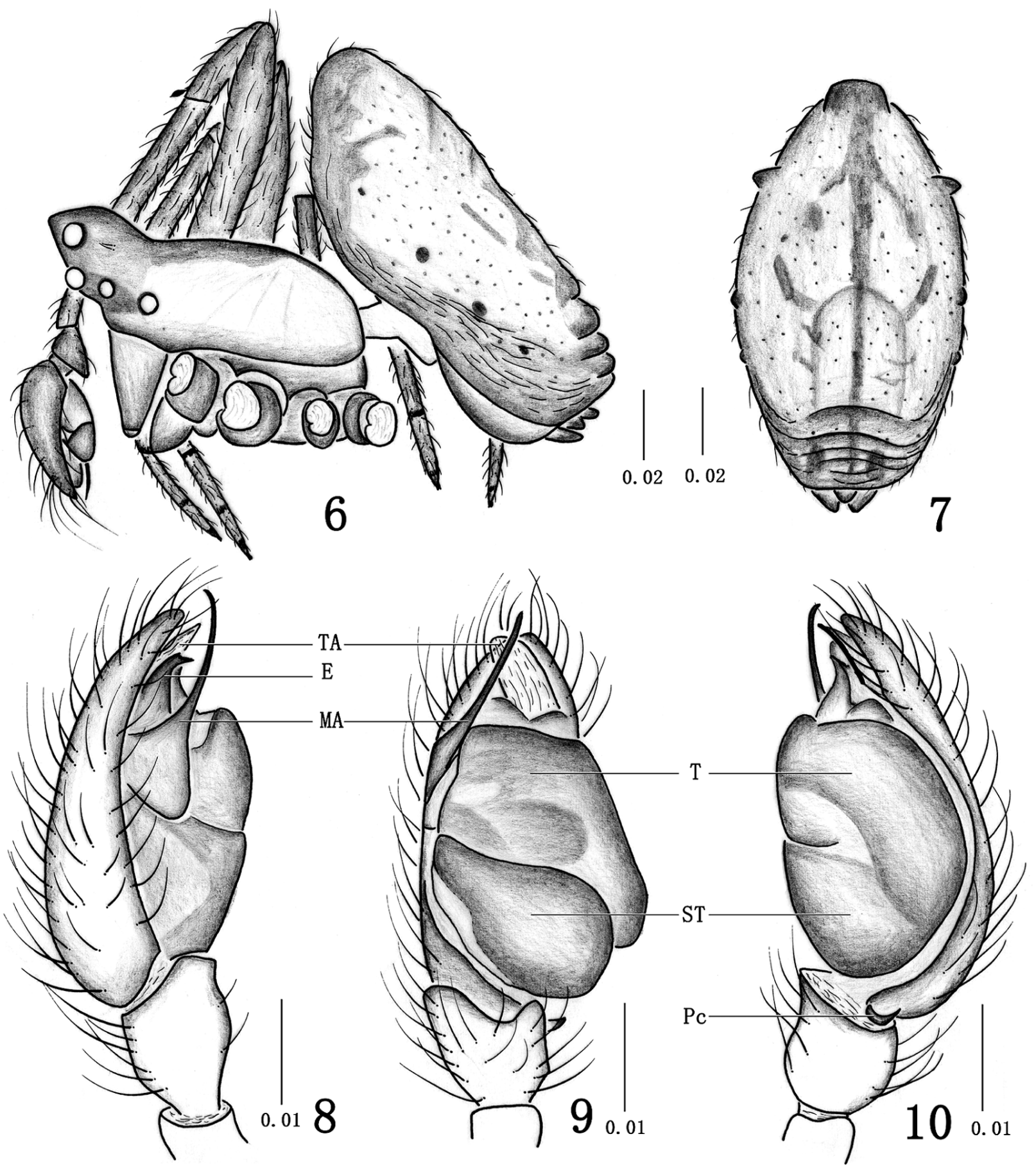

Figs. 6-10. Poltys hainanensis sp. nov., male holotype. - 6, body, lateral view; 7, abdomen, dorsal view; 8 , male palp, prolateral view; 9, same, ventral view; 10 , same, retrolateral view. (Scales: $1-2=0.02 \mathrm{~mm}, 3-5=0.01 \mathrm{~mm}$.)

and slender, with a broad base; paramedian apophysis is a pointed sclerotized bump (Figs. 3-5).

Variation. Total length 2.36-2.50.

Distribution. China (Hainan).

Etymology. The specific name refers to the ellipsoidal abdomen.
Poltys hainanensis sp. nov.

(Figs. 6-10)

Type series. Male holotype: Jianfeng National Nature Reserve, Ledong County, Hainan Province, China, $18^{\circ} 45^{\prime} \mathrm{N}$ $108^{\circ} 54^{\prime} \mathrm{E}$, June 2, 2009, Chao Zhang leg. (MHBU); paratypes: 3 males and 1 juvenile male, Diaoluoshan 

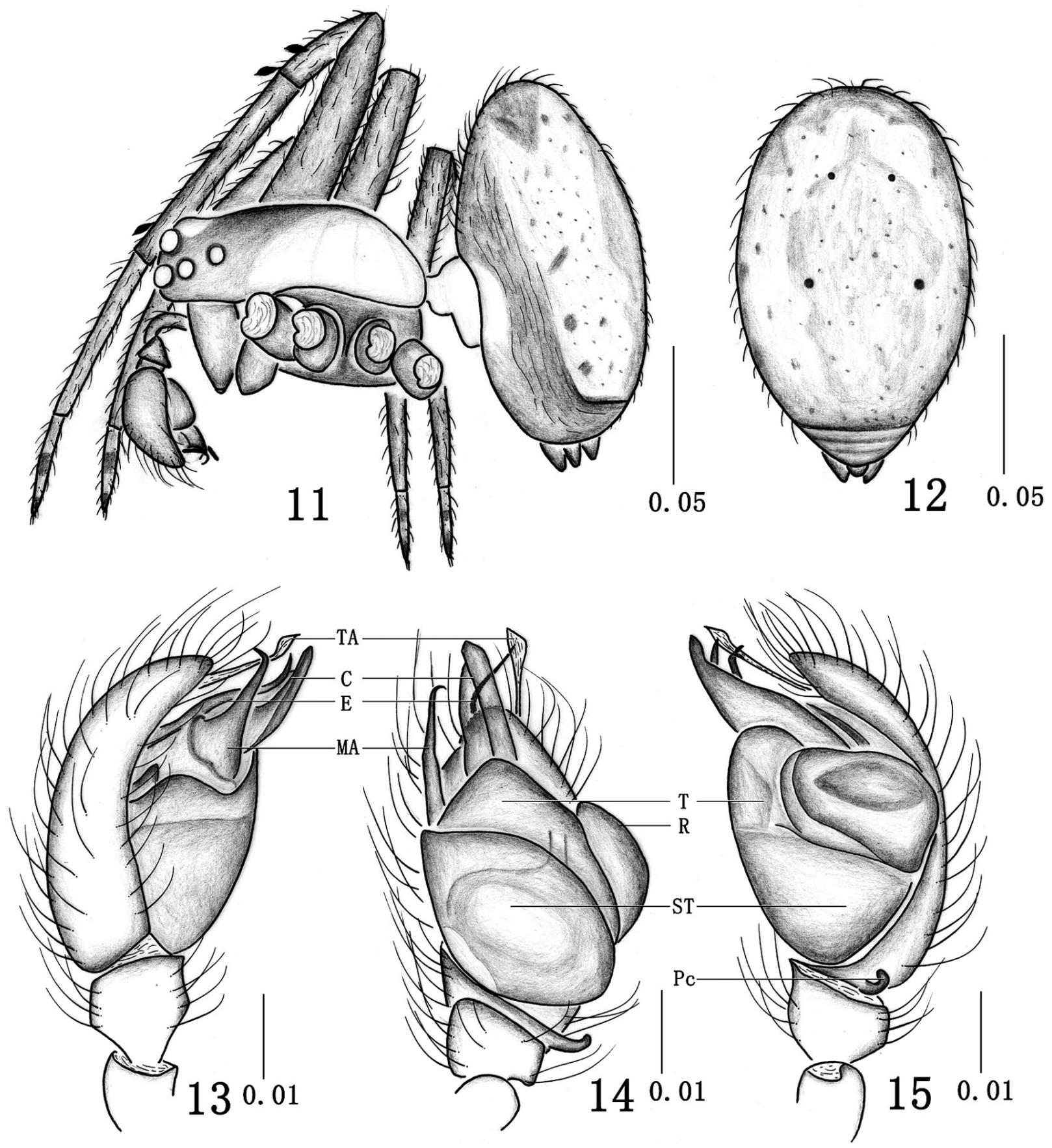

Figs. 11-15. Poltys pygmaeus sp. nov., male holotype. - 11, body, lateral view; 12, abdomen, dorsal view; 13, male palp, prolateral view; 14, same, ventral view; 15 , same, retrolateral view. (Scales: $1^{-2}=0.02 \mathrm{~mm}, 3^{-} 5=0.01 \mathrm{~mm}$.)

National Nature Reserve, Hainan Province, China, $18^{\circ} 43^{\prime} \mathrm{N}$ $109^{\circ} 52^{\prime} \mathrm{E}$, June 6, 2009, Guang-Xin Han and Xiao-Xiao Zhang leg. (MHBU); 2 males, Bawangling Town, Changjiang County, Hainan Province, China, $19^{\circ} 07^{\prime} \mathrm{N} 109^{\circ}$ $08^{\prime}$ E, May 23, 2009, Sheng-Tao Guo and Xiao-Xiao Zhang leg. (MHBU); 1 male, Fanjia Town, Danzhou County, Hainan Province, China, $19^{\circ} 20^{\prime} \mathrm{N} 109^{\circ} 40^{\prime}$ E, May 15, 2009 , Guang-Xin Han leg. (MHBU).

Diagnosis. This new species closely resembles $P$. columnaris Thorell, 1890, but can be distinguished from the latter by the relatively smaller and narrower ternimal apophysis; by the slim median apophysis; by palp organ without paramedian apophysis.

Description. Male holotype. Total length 2.05: carapace 0.85 long, 0.60 wide; abdomen 1.20 long, 0.70 wide. Carapace lightbulb-shape in dorsal view; highest at eye tubercle, latter massive and elevated (Fig. 6). Lateral carapace light brown, caput darkens slightly to eye tubercle, latter orange dorsally, carapace and caput with black median markings. Eye tubercle sagittate in dorsal view. Eye sizes 
and interdistances: AME 0.08, ALE 0.05, PME 0.07, PLE 0.06; AME-AME 0.09, AME-ALE 0.05, PME-PME 0.13, PME-PLE 0.23, ALE-PLE 0.07. MOA 0.22 long, anterior width 0.20 , posterior width 0.23 . Clypeal height much longer than AME diameter. Chelicera with 3 promarginal teeth. Chelicerae, labium, maxillae dark brown. Sternum yellow-brown with black edges. Legs yellow-orange with black rings and markings, all patellae and some tibiae with some macrosetae flattened into a small leaf-shape. Leg measurements: I $2.57(0.89+0.90+0.50+0.28)$; II 2.42 $(0.84+0.85+0.45+0.28)$; III $1.48(0.53+0.50+0.24+$ $0.21)$; IV $1.98(0.75+0.63+0.35+0.25)$. Leg formula: 1243. Abdomen longer than wide, rather lumpy, tall and ovoid, with slightly extended blunt apex and transverse pleat on posterior edge, widest at mid-height (Fig. 7). Dorsum of abdomen mostly grey-white with black speckling and dendriform markings. Brownish ventrally, black laterally. Palp: median apophysis filiform, broad basally; terminal apophysis broad, membranous flap; embolus short and stout (Figs. 8-10).

Variation. Total length 2.05-2.30.

Distribution. China (Hainan).

Etymology. The species name is a Latin adjective in apposition derived from the type locality.

Poltys pygmaeus sp. nov.

(Figs. 11-15)

Type series. Male holotype: Limushan National Nature Reserve, Qiongzhong County, Hainan Province, China, 19 ${ }^{\circ} 11^{\prime}$ N $109^{\circ} 43^{\prime}$ E, November 20, 2008, Ming-Sheng Zhu leg. (MHBU); paratypes: 1 male, Jianfeng Town, Ledong Town, Hainan Province, China, $18^{\circ} 45^{\prime} \mathrm{N} 108^{\circ} 54^{\prime} \mathrm{E}$, November 12 , 2008, Guang-Xin Han leg. (MHBU); 2 males, Jianfeng Town, Ledong Town, Hainan Province, China, $18^{\circ} 45^{\prime} \mathrm{N} 1$ $08^{\circ} 54^{\prime} \mathrm{E}$, June 1, 2009, Chao Zhang and Xiao-Xiao Zhang leg. (MHBU); 3 males, Bawangling Town, Changjiang County, Hainan Province, China, $19^{\circ} 07^{\prime} \mathrm{N} 109^{\circ} 08^{\prime} \mathrm{E}$, May 23, 2009, Guang-Xin Han and Sheng-Tao Guo leg. (MHBU).

Diagnosis. This new species closely resembles $P$. illepidus C. L. Koch, 1843, but can be distinguished from the latter by terminal apophysis departing from embolus; by the slim embolus; by the shape of conductor in male.

Description. Male holotype. Total length 2.43: carapace 1.08 long, 0.80 wide; abdomen 1.35 long, 0.90 wide. Carapace light brown with black median markings, eye tubercle poorly defined, broad and almost without any dip between caput and eye tubercle in lateral view (Fig. 11). Eye sizes and interdistances: AME 0.09, ALE 0.05, PME 0.08, PLE 0.06; AME-AME 0.10, AME-ALE 0.03, PME-PME 0.11, PME-PLE 0.16, ALE-PLE 0.07. MOA 0.22 long, anterior width 0.22 , posterior width 0.26 . Clypeal height low, shorter than AME diameter. Chelicera with 4 promarginal teeth. Chelicerae, labium, maxillae dark brown with white edges. Sternum black and hirsute. Legs yellow-orange with black rings and markings, all patellae and tibiae with some macrosetae flattened into a leaf-shape. Leg measurements: I $3.48(1.20+1.25+0.65+0.38)$; II $3.19(1.13+1.10+$ $0.60+0.36)$; III $1.81(0.65+0.63+0.30+0.23)$; IV 2.28 $(0.85+0.72+0.43+0.28)$. Leg formula: 1243 . Abdomen longer than wide, ovoid, with 2 pairs of brown sigilla midlongitudinally, black speckling and markings on a white ground (Fig. 12). Brown ventrally, black laterally. Palp: radix-stipes joint retrolateral; embolus rod-shaped, slender and curved; conductor large; terminal apophysis narrow at base, broadens to a lamina distally; median apophysis long and slender with a broad base (Figs. 13-15).

Variation. Total length 2.01-2.43.

Distribution. China (Hainan).

Etymology. The specific name refers to 2 pairs of brown sigilla of abdomen.

\section{Acknowledgments}

We are grateful to Dr. Chao Zhang, Mr. Sheng-Tao Guo, Ms. Xiao-Xiao Zhang and Ms. Jian-Yu Guo for the collection of specimens. The work was supported by the Ministry of Science and Technology of the People's Republic of China (2006FY110500-3).

\section{References}

Barrion, A. T. \& Litsinger, J. A. 1995. Riceland Spiders of South and Southeast Asia. CAB International, Wallingford, UK, 700 pp.

Bastawade, D. B. \& Khandal, D. 2006. Arachnida: Araneae (Spiders). In Fauna of Sanjay Gandhi National Park (Invertebrates) Borivali, Mumbai (Maharashtra), Conservation Area Series. Zool. Surv. India 26: 139-184.

Chrysanthus, P. 1961. Spiders from south New Guinea IV. Nova Guinea (N.S.) Zoology 10: 195-214.

Davies, V. T. 1988. An illustrated guide to the genera of orbweaving spiders in Australia. Memoirs of the Queensland Museum 25: 273332.

Murphy, F. \& Murphy, J. 2000. An Introduction to the Spiders of South East Asia with Notes on all the Genera. Malayan Nature Society, Kuala Lumpur, 625pp.

Platnick, N. I. 2010. The world spider catalog, version 10.5. American Museum of Natural History, online at http: //research. amnh.org/entomology/spiders/catalog/index.html.

Smith, H. M. 2005. A preliminary study of the relationships of taxa included in the tribe Poltyini (Araneae, Araneidae). J. Arachnol. 33: 468-481.

Smith, H. M. 2006. A revision of the genus Poltys in Australasia (Araneae: Araneidae). Rec. austral. Mus. 58: 43-96.

Song, D. X., Zhu, M. S. \& Chen, J. 1999. The Spiders of China Hebei Science and Technology Publishing House, Shijiazhuang, 640pp.

Tanikawa, A. 2007. An identification guide to the Japanese spiders of the families Araneidae, Nephilidae and Tetragnathidae. Arachnological Society of Japan, $121 \mathrm{pp}$.

Tanikawa, A. 2009. Hersiliidae. Nephilidae, Tetragnathidae, Araneidae. In Ono, H. (ed.), The Spiders of Japan with keys to the families and genera and illustrations of the species. Tokai Univ. Press, Kanagawa, pp. 149, 403-463

Yin, C. M., Wang J. F., Zhu M. S., Xie L. P., Peng X. J. \& Bao Y. H. 1997. Fauna Sinica: Arachnida: Araneae: Araneidae. Science Press, Beijing, $460 \mathrm{pp}$

Received April 18, 2010 / Accepted September 3, 2010 